\title{
Desenvolvimento de um quebra-cavacos para a operação de roscamento do aço ABNT 4133 modificado
}

\author{
Development of a chip breaker for external \\ threading of modified ABNT 4133 steel
}

\author{
Alexandre Martins de Noronha ${ }^{1,2}$, Luis Fernando Bittencourt Said ${ }^{1}$, \\ Jochen Peter Ames ${ }^{1}$, Julio Cesar da Silva ${ }^{1}$ \\ Alexandre Mendes Abrão ${ }^{2}$
}

\author{
${ }^{1}$ Vallourec Tubos do Brasil, Av. Olinto Meireles, 65, 30640-010 Belo Horizonte, MG \\ e-mail: alexandre.noronha@vallourec.com; luis.said@vallourec.com; jochen.ames@vallourec.com; \\ juliocesar.silva@vallourec.com \\ ${ }^{2}$ Programa de Pós Graduação Engenharia Mecânica,Universidade Federal de Minas Gerais, Av. Antônio Carlos, 6627, \\ 31270-901, Belo Horizonte, MG \\ e-mail: abrao@ufmg.br
}

\section{RESUMO}

O setor de óleo e gás vem ampliando seu mercado nos últimos anos devido a uma demanda cada vez maior por recursos de energia. Descobertas na região do pré-sal estão exigindo a prospecção de poços de maior profundidade usando tubos com maior resistência a pressões elevadas e para atuarem em ambientes corrosivos. Todo esse cenário faz com que novos aços e novas roscas sejam desenvolvidos, aumentando a geração de cavacos e a complexidade de sua quebra, além de trazer problemas de manutenção das roscadeiras e de segurança para os operadores de máquinas ferramentas. Apesar de todo esse período de desenvolvimento no segmento de tubos petrolíferos, pouco se estudou sobre quebra-cavacos mecânicos específicos para esse setor. Com isso, acaba-se utilizando quebra-cavacos de catálogo que não foram projetados especificamente para a aplicação citada, que e consequentemente, promovem a formação de cavacos em forma de fita emaranhada. Este trabalho foi focado no desenvolvimento de quatro quebra-cavacos, baseando-se na região de desgaste da superfície de saída da ferramenta de roscamento e, consequentemente, alterando a distância do quebracavacos da aresta de corte. Os quatro quebra-cavacos desenvolvidos e um modelo já existente no mercado foram testados. Durante os testes os parâmetros de corte (velocidade de corte, profundidade de usinagem e sobremetal de torneamento) variaram com intuito de se analisar seu impacto na eficiência da quebra dos cavacos e qualidade da peça. Os resultados mostraram que os quebra-cavacos mais próximos da aresta de corte foram os mais eficientes na quebra dos cavacos, os valores de sobremetal não influenciaram a quebra e a profundidade de usinagem foi a variável que mais afetou a qualidade da rosca. Finalmente, não foi possível encontrar nenhuma variação no consumo de potência do motor do eixo principal comparando o quebra-cavacos desenvolvido com o quebra-cavacos original. Com isso, foi possível produzir cavacos curtos, melhorar a segurança da operação de roscamento e a manutenção das máquinas.

Palavras-chave: Quebra-cavacos, roscamento, petrolífero.

\section{ABSTRACT}

The oil and gas market has increased during the last years due to a higher demand for energy resources. Presalt areas require deeper wells, pipes more resistant to internal and external pressures, high temperatures and also to corrosive environment. This scenario requested the development of new steel grades and new designs for threaded connections, thus increasing chips formation and the difficulty to break them. It brought issues for conveyors maintenance and safety risks for machine operators. Despite this period of intensive development in the oil and gas market, only a few studies for chip breakers specifically designed for this application have been conducted. In general, pipe manufacturers buy chip breakers from off-the-shelf, i. e. chip breakers that were not designed for this segment, thus not providing optimum results. This work is concerned with the development of a chip breaker, based on the rake face wear of the threading tool. The approach is to change 
the distance of the chip breaker from the cutting edge. Four developed chip breakers and a commercial one were tested. During the tests, cutting speed, depth of cut and allowance were varied in order to assess their impact on chip breaking effectiveness and work piece quality. The results show that the closer the chip breaker to the cutting edge, the more efficient they were in breaking the chips, the allowance had not any influence and depth of cut was the most influent factor thread quality. Finally, it was not possible to identify any variation in power consumption of the main spindle when the chip breaker was changed.

Keywords: Chip breaker, threading, oil and gas.

\section{INTRODUÇÃO}

Com a crescente demanda global por energia, o setor de óleo e gás conta com uma série de oportunidades e enfrenta desafios nas áreas de exploração, transformação do material bruto, logística e serviços no campo petrolífero. Os investimentos nesse segmento aumentaram consideravelmente em comparação às últimas décadas. A Agência Nacional do Petróleo (ANP) anunciou no início de 2014 um investimento de R\$ 30 bilhões em pesquisa nos próximos dez anos, enquanto a principal empresa petroleira brasileira vem anunciando investimentos de US\$220,6 bilhões para os próximos cinco anos. A descoberta da região do pré-sal impulsionou os investimentos em pesquisa, uma vez que trouxe uma maior complexidade operacional. Estima-se que 52\% da produção de barris de petróleo no Brasil em 2018 será oriunda da região do pré-sal [1].

Os poços na região do pré-sal possuem uma profundidade bem maior que os da região habitual de exploração. Com isso as pressões externas e internas nas colunas de tubo aumentam significativamente. Além disso, o ambiente dessa região é mais corrosivo, contendo gases que exigem colunas de aço com materiais de maior resistência. Devido a esse aumento da demanda do mercado juntamente com novas exigências de aplicação, os últimos anos foram marcados por desenhos de várias novas conexões e em aços de maior complexidade para usinagem. Portanto, a dificuldade em se quebrar o cavaco também aumentou e tornou-se necessário o estudo de novas geometrias de quebra-cavacos.

De acordo com Jawahir e van Luttervelt [2], até a década de 1940 pouca importância foi dada à retirada do cavaco e os maiores esforços eram dedicados ao desgaste da ferramenta e às forças de corte. Na década de 50 os primeiros estudos relacionados ao fluxo do cavaco e ao uso de dispositivos para quebra do mesmo ganharam força. A década de 60 trouxe a novidade dos estudos de mecanismos de usinagem que reduziam ao máximo o contato das ferramentas de corte. A década de 70 foi o período de maior intensidade nos estudos de fluxo e curvatura do cavaco além dos dispositivos de quebra-cavacos mecânico, juntamente com desgaste de ferramenta, forças de corte e qualidade da peça. Durante a década de 80 estes estudos perderam intensidade, mas os fabricantes de ferramentas de metal duro continuaram os desenvolvimentos para novas geometrias dos quebra-cavacos mecânicos. Desde a década de 90 até os dias de hoje, percebe-se que ainda necessita-se de diversos estudos na área para um controle do cavaco, sendo que muito pouco foi estudado para a quebra do cavaco durante o roscamento para o setor de óleo e gás.

Três tipos de ferramenta são normalmente utilizados para o roscamento: pastilha de perfil completo, pastilha de perfil parcial ou em $\mathrm{V}$ e pastilha multiarestas. A pastilha de perfil completo, como o próprio nome já diz, gera o perfil completo da rosca incluindo a crista, não sendo necessárias operações posteriores de rebarbação. Porém, para cada passo e perfil de rosca é necessária uma pastilha diferente, aumentando assim o inventário. Uma solução para redução de inventários é a pastilha de perfil parcial. O setor de óleo e gás geralmente utiliza a pastilha multiarestas, que se assemelha a pastilha de perfil completo, mas possui duas pontas (dentes) ou mais. Estudos mostram que desde a década de 60 esse tipo de pastilha é usado mundialmente no setor de óleo e gás por permitir maior produtividade, mas em contrapartida aumenta a geração de cavaco e a complexidade de seu controle [3]. Qualquer um dos três tipos de ferramenta pode penetrar na peça de quatro maneiras diferentes: penetração de flanco modificado, penetração de flanco, penetração radial e penetração alternada pelos flancos. A escolha do método é essencial para um melhor controle do cavaco, vida da ferramenta e qualidade da peça. A penetração por flanco modificado e a penetração por flanco são as mais indicadas para controle do cavaco [4].

EZUGWU et al. [5] atribuem a complexidade da operação de roscamento ao desgaste de ferramenta e citam que a cobertura auxilia na redução do coeficiente de atrito na região de geração do cavaco. Por outro lado, CHAWLA [6] mostra que à medida que a rugosidade da ferramenta aumenta, a quebra do cavaco melhora pois gera maior atrito, aumentando assim a tensão para quebra do cavaco. Os catálogos dos principais fornecedores de ferramenta mostram que a pressão excessiva na aresta e ou a quebra da pastilha no roscamento podem ser causadas por profundidades de usinagem muito baixas em materiais endurecidos e devido a um controle de cavaco ineficaz [7]. SAOTOME et al. [] afirmam que o desgaste de ferramentas de roscamento é muito mais acentuado que em ferramentas de torneamento e faceamento devido ao maior contato 
entre a aresta de corte e a peça. ZHOU et al. [9] enfatizam que em aproximadamente $50 \%$ dos casos a vida de uma ferramenta de carboneto de tungstênio é determinada por quebra prematura. Os principais motivos são os parâmetros de corte mal escolhidos e o cavaco em fitas gerado. CHEN et al. [10], citam que o roscamento é uma das etapas mais complexas e que a quebra da ponta da ferramenta é muito comum, principalmente quando se utiliza ferramentas multiarestas e com alturas diferentes, pois todas as arestas removem material e estão expostas ao cavaco.

ZHOU [11] definiu uma região de quebra do cavaco baseada na relação entre avanço e profundidade de usinagem durante o torneamento de um aço ao carbono. Para promover a quebra do cavaco os valores de avanço devem estar acima de $0,2 \mathrm{~mm} / \mathrm{rev}$ e os valores de profundidade de usinagem devem exceder 0,82 $\mathrm{mm}$. Apesar do aço utilizado por ZHOU [11] ser diferente do aço estudado nesse artigo, os dois são aços ao carbono e submetidos ao mesmo tratamento térmico, podendo apresentar semelhanças no comportamento da quebra do cavaco. No caso de roscamento de peças metálicas para o setor de óleo e gás, os valores de avanço são definidos pelo passo da conexão e bastante superiores ao valor limite de avanço, porém os valores de profundidade de usinagem são inferiores a $0,82 \mathrm{~mm}$, pois a ferramenta não resistiria a valores de profundidade de usinagem tão elevados. A forma dos cavacos no roscamento de peças metálicas temperadas se assemelha a helicoidal do tipo arruela emaranhado. Portanto, somente uma alteração nas condições de corte não é suficiente para quebra do cavaco, sendo necessárias intervenções mecânicas com os dispositivos quebracavacos.

\section{MATERIAIS E MÉTODOS}

O aço ABNT 4133 modificado foi selecionado para confecção dos corpos de prova, e possui a seguinte faixa de composição básica: 0-0,35\% C, 0-1\% Mn, 0,012-0,055\% Al, 0-0,02 \% P, 0-0,15\% Cu, 0,8-1,5\% Cr, 0,4$1,0 \% \mathrm{Mo}, 0,025-0,04 \% \mathrm{Nb}, 0-0,15 \% \mathrm{Ni}, 0,005-0,02 \% \mathrm{Ti}, 0,04-0,07 \% \mathrm{~V}$, dureza média de 30 HRC e limite de escoamento médio de $800 \mathrm{MPa}$ [12]. As principais diferenças de composição que caracterizam o aço como modificado é a adição de níquel e vanádio e uma quantia superior de molibdênio. A escolha desse aço se deve ao fato do mesmo ser muito utilizado nas operações de exploração de petróleo devido à resistência em ambientes corrosivos. Foram utilizados tubos sem costura com diâmetro externo de 244,5 mm e espessura de parede de 13,84 $\mathrm{mm}$ para os testes de quebra do cavaco.

A ferramenta de corte usada nos testes de roscamento pertence a uma patente $\mathrm{VAM}^{\circledR}$, possui quatro arestas de corte (passo de 5,08 mm) e é utilizada para o desbaste da rosca (Figura 1). A ferramenta é fabricada apenas para uso interno na empresa Vallourec e por isso não possui código para fins comerciais. Trata-se de uma classe de metal duro com cobertura de nitreto de titânio (TiN).

Para os testes de roscamento com o quebra-cavacos desenvolvido inicialmente foi utilizado um torno que produz peças curtas, como por exemplo, luvas conectoras. Essa escolha foi feita para se eliminar a influência de outras variáveis que poderiam afetar a análise da quebra do cavaco, como por exemplo, o leito de rolos e o empeno de corpo para tubos de grande comprimento. $\mathrm{O}$ torno utilizado nessa etapa de experimentos foi o Mazak Power Master, com rotação máxima de 725 rpm, potência do motor principal de 37 kW e comando numérico computadorizado MAZATROL 640T. A placa utilizada é pneumática do fornecedor Kitagawa.

Ao término da fase inicial dos experimentos, um segundo torno foi utilizado em campanha normal de produção de tubos com comprimento de 12 metros com intuito de analisar o impacto do leito de rolos e do empeno do corpo do tubo. O torno utilizado na segunda e terceira etapa foi o Mori Seiki SL-803 com rotação máxima de 500 rpm, potência do motor principal de $45 \mathrm{~kW}$, e comando numérico computadorizado FANUC 21. A placa utilizada é pneumática do fornecedor SMW.

O fluido de corte utilizado durante a operação de roscamento foi o óleo sintético Hocut ${ }^{\circledR}$ MAX WSH do fabricante Houghton. A recomendação do fabricante é de se trabalhar com uma concentração de 3\% a 7\% e durante os experimentos a concentração foi mantida em $5 \%$.

Para a análise da ferramenta e do quebra-cavacos utilizou-se uma lupa estereoscópica Olympus modelo SZX10 ${ }^{\circledR}$. Uma câmera digital do mesmo fabricante (modelo UC30) foi acoplada à lupa com intuito de registrar as imagens.

Uma mola de fabricação própria instalada no interior do tubo foi ocasionalmente utilizada para reduzir vibrações e evitar trepidação durante os testes de roscamento. 


\subsection{Desenvolvimento do quebra-cavacos}

O quebra-cavacos normalmente utilizado em produção situa-se muito distante da aresta de corte, contribuindo para a suspeita de que o mesmo não é efetivo na quebra e, por consequência, produzindo cavacos em fita emaranhados. A Figura 1 mostra o posicionamento do quebra-cavacos em relação à ferramenta de corte, onde se percebe a distância elevada do quebra-cavacos à aresta de corte. Percebe-se pela Figura 2 que após o roscamento a ferramenta de corte apresenta marcas em sua superfície de saída. Essas marcas são provavelmente devido ao atrito do cavaco com a superfície de saída. A região que não apresenta essas marcas indica que a lamela do cavaco já se curvou e não está mais escorregando sobre a superfície de saída. Nota-se que a região que tem as marcas de atrito é muito pequena comparada à distância do quebra-cavacos à aresta de corte, comprovando a suspeita de que o quebra-cavacos original não é eficiente, devido à lamela se curvar antes de atingir o quebra-cavacos.

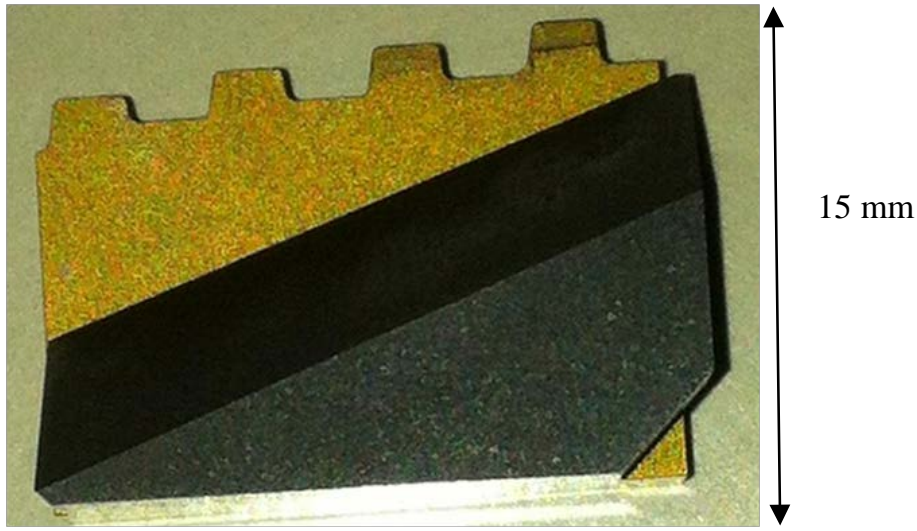

Figura 1: Posicionamento do quebra-cavacos original na ferramenta de corte.

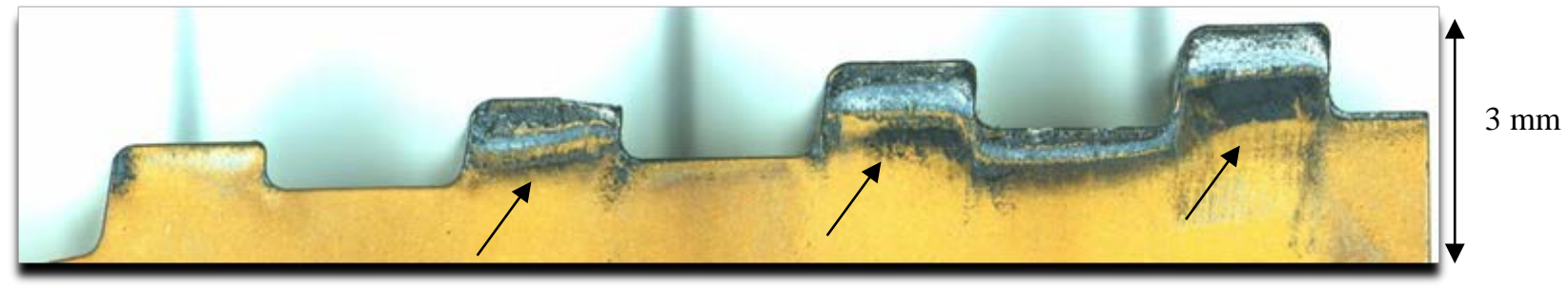

Figura 2: Região de desbaste da superfície de saída e marcas de desgaste.

Baseado nessas constatações, cinco ferramentas de corte foram analisadas na lupa estereoscópica após o fim da vida. O fim da vida das ferramentas foi determinado pelo operador da máquina, podendo ter dois principais motivos: o operador ao passar a mão na ferramenta percebeu que a mesma estava quebrada ou as peças que estavam sendo produzidas estavam tendo variações dimensionais que indicavam um desgaste da ferramenta. Cada uma das quatro arestas das cinco ferramentas foi analisada com relação às marcas na superfície de saída, visando se determinar a distância média em que o cavaco ainda está deslizando sobre a superfície de saída.

Empregando-se essa mesma metodologia para os demais dentes da ferramenta, chegou-se ao desenho do quebra-cavacos. Para realização dos testes foram desenvolvidos três quebra-cavacos com o mesmo desenho, variando apenas a distância do quebra-cavacos à aresta de corte e um quarto conceito de quebra-cavacos teve uma alteração no ângulo do flanco lateral de cada dente. O quebra-cavacos desenvolvido está ilustrado na Figura 3 (montado na cápsula sobre a ferramenta de roscamento). 

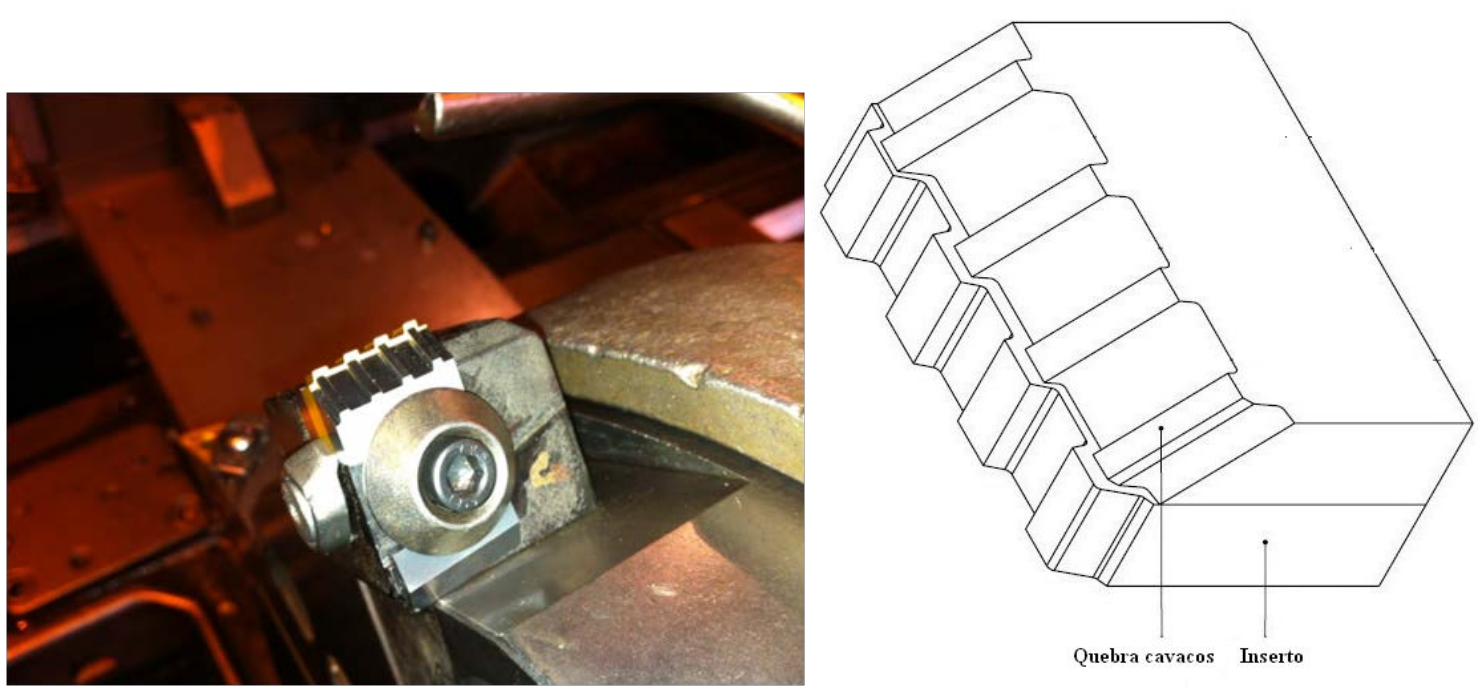

Figura 3: Quebra-cavacos montado sobre a ferramenta.

\subsection{Etapas de testes}

A Tabela 1 contém um resumo das principais características de cada quebra-cavacos testado. Os quebracavacos codificados como QC-90, QC-91, QC-92 e QC-93 são os que foram desenvolvidos durante esse trabalho. A única diferença entre os quebra-cavacos QC-90, QC-91 e QC-93 é a distância que estes ficam da aresta de corte. O quebra-cavacos QC-92 possui a mesma distância da aresta de corte que o quebra-cavacos QC-91, porém tem os flancos dos dentes chanfrados em 30. O quebra-cavacos código C-4001-4 produzido pelo fornecedor Seco Tools [4] , que se assemelha ao quebra-cavacos desenvolvido neste projeto, mas possui altura menor, ou seja, maior distância da aresta de corte, formato dos dentes diferente e largura do quebracavacos menor também foi testado.

Tabela 1: Característica dos quebra-cavacos utilizados.

\begin{tabular}{|c|c|c|c|c|c|}
\hline $\begin{array}{c}\text { Quebra- } \\
\text { cavacos }\end{array}$ & $\begin{array}{c}\text { Comprimento } \\
\text { (mm) }\end{array}$ & $\begin{array}{c}\text { Distância } \\
\text { da aresta } \\
\text { de corte } \\
\text { (mm) }\end{array}$ & $\begin{array}{c}\text { Largura } \\
\text { (mm) }\end{array}$ & Ângulo & Observações \\
\hline QC-90 & 20,05 & 0,80 & 5,00 & $45^{\circ}$ & - \\
\hline QC-91 & 20,05 & 1,00 & 5,00 & $45^{\circ}$ & - \\
\hline QC-92 & 20,05 & 1,00 & 5,00 & $45^{\circ}$ & $\begin{array}{c}\text { Flancos dos dentes chanfra- } \\
\text { dos em } 30^{\circ}\end{array}$ \\
\hline QC-93 & 20,05 & 2,00 & 5,00 & $45^{\circ}$ & - \\
\hline C-4001-4 & 19,80 & 3,30 & 3,97 & $45^{\circ}$ & Fábricado pela Seco Tools \\
\hline
\end{tabular}

A avaliação de desempenho do quebra-cavacos foi baseada em três parâmetros: eficiência na quebra dos cavacos, qualidade da peça e potência exigida no motor do eixo principal. A eficiência da quebra dos cavacos foi avaliada visualmente durante o roscamento. Se durante a usinagem o cavaco formou uma fita contínua a quebra foi considerada ineficiente, enquanto se o cavaco ficou curto (60 a $150 \mathrm{~mm}$ ) a quebra foi considerada eficiente. Cada passada durante o roscamento foi avaliada.

Para verificação da qualidade da peça durante os testes apenas o quesito de trepidação foi levado em consideração, pois a utilização do quebra-cavacos não influencia os parâmetros dimensionais da rosca. Apenas a rugosidade e a trepidação poderiam ser afetadas pelo uso do quebra-cavacos. Contudo, segundo DINIZ et al. [13] , variações da velocidade de corte acima de $100 \mathrm{~m} / \mathrm{min}$ pouco influenciam a rugosidade. O procedimento de medição de trepidado utilizado é subjetivo e depende da experiência do inspetor, já que consiste 
em passar a ponta de uma lapiseira na região suspeita de trepidação. Qualquer atrito que ocorra durante essa movimentação é motivo de recusa.

As Figuras 4 e 5 ilustram, respectivamente, os padrões adotados na verificação da eficiência da quebra do cavaco e na qualidade da peça para fins de comparação entre os resultados. Os testes que receberam a classificação "A” na eficiência da quebra do cavaco e na qualidade da peça são os que apresentaram melhor resultado, enquanto os testes que receberam a classificação "E” nas duas categorias são os de pior resultado.

Para verificação de possíveis efeitos secundários do uso do novo conceito de quebra-cavacos aplicado nesse estudo, mediu-se o percentual de potência nominal do motor do eixo principal consumido durante a usinagem. Essa potência foi armazenada em um software chamado PIMS (Sistema de Gerenciamento das Informações do Processo - "Process Information Management System”).
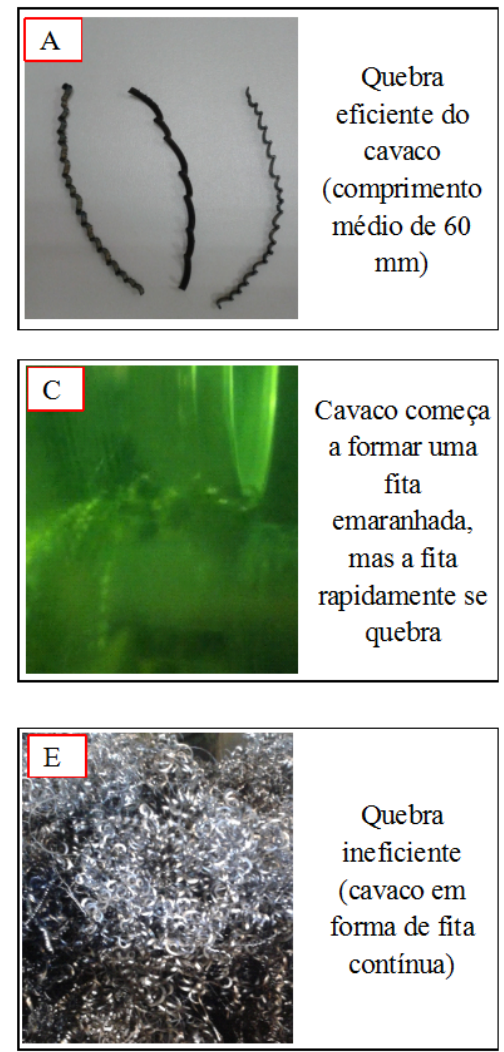
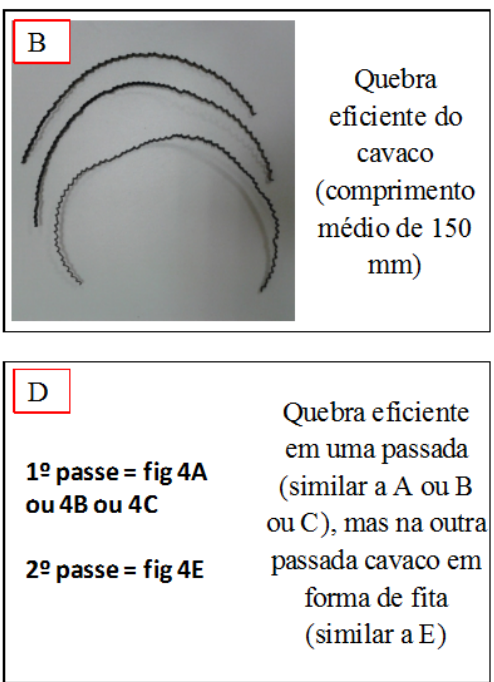

10 passe $=$ fig $4 \mathrm{~A}$

em uma passada (similar a A ou B ou C), mas na outra forma de fita (similar a E)

Figura 4: Padrão de classificação dos testes com relação à eficiência na quebra dos cavacos. 

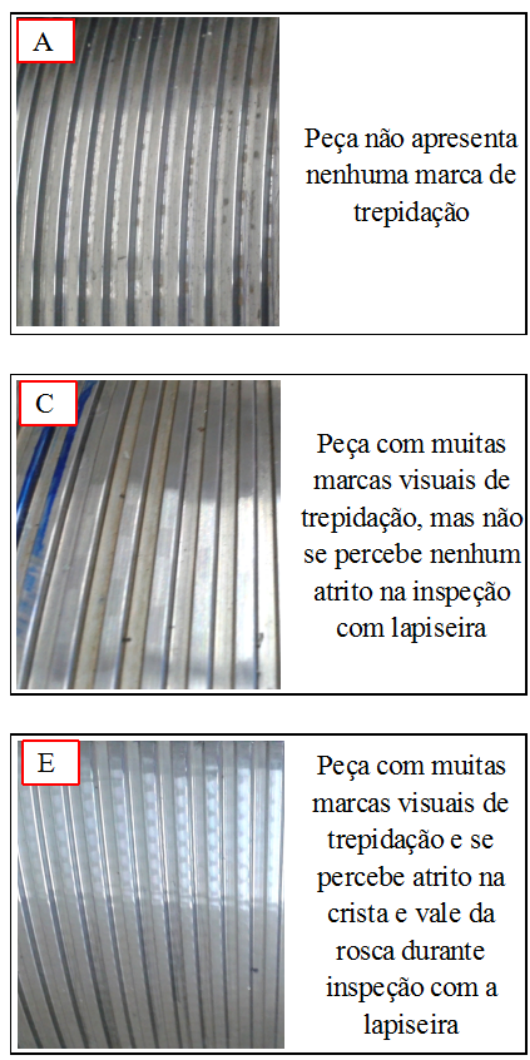
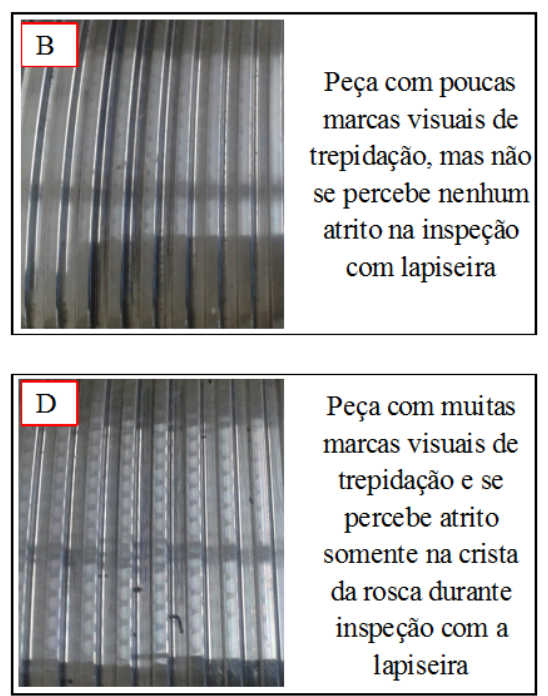

Figura 5: Padrão de classificação dos testes com relação à qualidade da peça.

Os testes foram divididos em três etapas, entretanto, é importante salientar que os parâmetros utilizados em cada teste não foram selecionados com base em um planejamento estatístico, mas em função do resultado obtido no teste anterior e nos valores tipicamente empregados na operação de roscamento do aço ABNT 4133 modificado. Na primeira etapa o foco principal foi na quebra do cavaco, portanto não foi feito nenhum ajuste nos parâmetros de corte visando redução da trepidação. O objetivo foi encontrar o melhor cenário para quebra do cavaco independentemente da qualidade da peça. Nessa etapa optou-se por roscar peças curtas, eliminando assim a necessidade de leitos, pois estes poderiam influenciar o processo. Além disso, peças curtas diminuem os impactos de não conformidades da matéria-prima, como por exemplo, empeno de corpo. A Tabela 2 mostra os parâmetros utilizados na primeira etapa de testes. A variável denominada $a_{p 1}$ é a profundidade de corte da primeira passada de rosca, sendo que a profundidade final da rosca é $1,3 \mathrm{~mm}$, ou seja, para os valores de $a_{p 1}=0,65 \mathrm{~mm}$, significa que as duas passadas de roscamento tiveram profundidades iguais. Inicialmente utilizou-se um único modelo de quebra-cavacos e um valor de velocidade de corte fixo variando apenas a profundidade de usinagem. Com base nos melhores resultados de eficiência na quebra dos cavacos, o valor da profundidade de usinagem foi fixado e variou-se os modelos de quebra-cavacos e as velocidades de corte. 
Tabela 2: Parâmetros de corte da primeira etapa de testes.

\begin{tabular}{|c|c|c|c|c|}
\hline Teste & Quebra-cavacos & $\begin{array}{c}\text { Velocidade } \\
\mathbf{d e} \text { corte } \\
\mathbf{( m / m i n )}\end{array}$ & $\begin{array}{c}\text { Antivibratório } \\
\text { (mola) }\end{array}$ & $\begin{array}{c}\boldsymbol{a}_{\mathbf{p} 1} \\
\mathbf{( m m})\end{array}$ \\
\hline 1 & QC-90 & 165 & Não & 0,13 \\
\hline 2 & QC-90 & 165 & Não & 0,32 \\
\hline 3 & QC-90 & 165 & Não & 0,65 \\
\hline 4 & QC-91 & 120 & Sim & 0,65 \\
\hline 5 & QC-91 & 140 & Sim & 0,65 \\
\hline 6 & QC-91 & 140 & Sim & 0,65 \\
\hline 7 & QC-92 & 120 & Sim & 0,65 \\
\hline 8 & QC-92 & 160 & Sim & 0,65 \\
\hline 9 & QC-93 & 120 & Sim & 0,65 \\
\hline 10 & QC-93 & 140 & Sim & 0,65 \\
\hline 11 & QC-90 & 120 & Sim & 0,65 \\
\hline 12 & QC-90 & 140 & Sim & 0,65 \\
\hline 13 & QC-90 & 120 & Sim & 0,32 \\
\hline 14 & C-4001-4 & 120 & Sim & 0,65 \\
\hline 15 & C-4001-4 & 160 & Sim & 0,65 \\
\hline
\end{tabular}

A segunda etapa de testes teve o intuito de validar o experimento e verificar a influência de outras variáveis no processo de quebra do cavaco e qualidade da peça, como por exemplo, sobremetal durante o torneamento $\left(\mathrm{SM}_{\mathrm{T}}\right)$, sobremetal durante o roscamento $\left(\mathrm{SM}_{\mathrm{D}}\right)$, velocidade de corte e profundidade de usinagem em cada passada de roscamento. Apenas os quebra-cavacos QC-90 e QC-91 foram testados nessa segunda etapa, pois foram os que apresentaram melhor desempenho na quebra do cavaco durante a primeira fase. Além disso, nessa etapa de testes utilizaram-se tubos com comprimento de 12 metros, aumentando assim a complexidade do processo e influência de outras variáveis. A Tabela 3 mostra os parâmetros utilizados na segunda etapa de testes. Inicialmente os valores de velocidade de corte, profundidade de usinagem e modelo de quebra-cavacos foram mantidos os mesmos, enquanto os valores de sobremetal de torneamento e desbaste de rosca variaram. Com base nos resultados de eficiência da quebra dos cavacos e qualidade da peça, os valores de sobremetal foram fixados e iniciou-se uma variação dos parâmetros de modelo do quebra-cavacos, profundidade de usinagem e velocidade de corte, nessa ordem. 
Tabela 3: Parâmetros de corte da segunda etapa de testes.

\begin{tabular}{|c|c|c|c|c|c|}
\hline Teste & Quebra-cavacos & $\mathbf{N}^{\circ}$ Passes & $\begin{array}{l}\text { Velocidade de } \\
\text { corte }[\mathrm{m} / \mathrm{min}]\end{array}$ & $\begin{array}{c}\mathrm{SM}_{\mathrm{T}} / \mathrm{SM}_{\mathrm{D}} \\
{[\varnothing \mathrm{mm}]}\end{array}$ & $a_{p 1}[\mathrm{~mm}]$ \\
\hline 16 & QC-90 & 2 & 120 & 0,15 / 0,03 & 0,35 \\
\hline 17 & QC-90 & 2 & 120 & $0,10 / 0,03$ & 0,35 \\
\hline 18 & QC-90 & 2 & 120 & $0,10 / 0,00$ & 0,35 \\
\hline 19 & QC-90 & 2 & 160 & $0,10 / 0,05$ & 0,35 \\
\hline 20 & QC-90 & 2 & 160 & $0,10 / 0,05$ & 0,35 \\
\hline 21 & QC-90 & 2 & 170 & $0,10 / 0,05$ & 0,35 \\
\hline 22 & QC-91 & 2 & 170 & $0,10 / 0,05$ & 0,35 \\
\hline 23 & QC-91 & 2 & 170 & $0,10 / 0,05$ & 0,65 \\
\hline 24 & QC-91 & 2 & 140 & $0,10 / 0,05$ & 0,65 \\
\hline 25 & QC-90 & 2 & 140 & $0,10 / 0,05$ & 0,65 \\
\hline 26 & QC-91 & 2 & 120 & $0,10 / 0,05$ & 0,65 \\
\hline 27 & QC-91 & 2 & 120 & $0,20 / 0,05$ & 0,65 \\
\hline 28 & QC-91 & 2 & 120 & $0,10 / 0,05$ & 0,80 \\
\hline 29 & QC-91 & 2 & 100 & $0,10 / 0,05$ & 1,00 \\
\hline 30 & QC-91 & 2 & 100 & $0,10 / 0,05$ & 0,25 \\
\hline 31 & QC-91 & 2 & 90 & 0,10 / 0,05 & 0,40 \\
\hline 32 & QC-91 & 2 & 120 & $0,10 / 0,05$ & 0,40 \\
\hline 33 & QC-91 & 2 & 100 & $0,10 / 0,05$ & 0,50 \\
\hline 34 & QC-91 & 2 & 110 & 0,10 / 0,05 & 0,50 \\
\hline 35 & QC-91 & 2 & 130 & $0,10 / 0,05$ & 0,50 \\
\hline 36 & QC-91 & 2 & 140 & $0,10 / 0,05$ & 0,50 \\
\hline 37 & QC-91 & 1 & 110 & $0,10 / 0,05$ & 1,30 \\
\hline 38 & QC-90 & 2 & 140 & $0,10 / 0,05$ & 0,50 \\
\hline
\end{tabular}

A terceira etapa de testes visou a validação final do procedimento. A principal diferença dessa etapa comparada com a segunda etapa é que apenas os parâmetros que apresentaram maior influência no processo foram analisados novamente. Além disso, a faixa dos valores de cada parâmetro foi mais restrita baseada nos melhores resultados (quebra do cavaco e qualidade da peça) obtidos na segunda etapa de testes. A Tabela 4 mostra os parâmetros que variaram no roscamento das nove peças. Inicialmente os valores de velocidade de corte e modelo de quebra-cavacos foram mantidos, variando-se apenas a profundidade de usinagem. Com base nos melhores resultados de eficiência na quebra dos cavacos e qualidade das peças, os melhores valores de profundidade de usinagem foram mantidos e variou-se a velocidade de corte. Finalmente, variou-se os modelos de quebra-cavacos. 
Tabela 4: Parâmetros de corte da terceira etapa de testes.

\begin{tabular}{|c|c|c|c|c|}
\hline Teste & Quebra-cavacos & $\mathbf{N}^{\circ}$ passes & $\begin{array}{r}\text { Velocidade de } \\
\text { corte [m/min] }\end{array}$ & $\boldsymbol{a}_{\boldsymbol{p} 1}[\mathbf{m m}]$ \\
\hline 39 & QC-90 & 2 & 160 & 0,5 \\
\hline 40 & QC-90 & 2 & 160 & 0,65 \\
\hline 41 & QC-90 & 2 & 160 & 0,8 \\
\hline 42 & QC-90 & 1 & 160 & 1,3 \\
\hline 43 & QC-90 & 2 & 150 & 0,65 \\
\hline 44 & QC-90 & 2 & 150 & 0,8 \\
\hline 45 & QC-91 & 2 & 120 & 0,5 \\
\hline 46 & QC-91 & 2 & 130 & 0,4 \\
\hline 47 & QC-91 & 2 & 120 & 0,25 \\
\hline
\end{tabular}

\section{RESULTADOS}

A Figura 6 contém um resumo dos resultados da primeira etapa de testes com quinze corpos de prova sob as condições de corte indicadas na Tabela 2. A Figura 7 contém um resumo dos resultados da segunda etapa com 23 testes de roscamento sob as condições de corte indicadas na Tabela 3. A Figura 8 contém um resumo dos resultados dos nove testes da terceira etapa, realizados sob as condições descritas na Tabela 4.

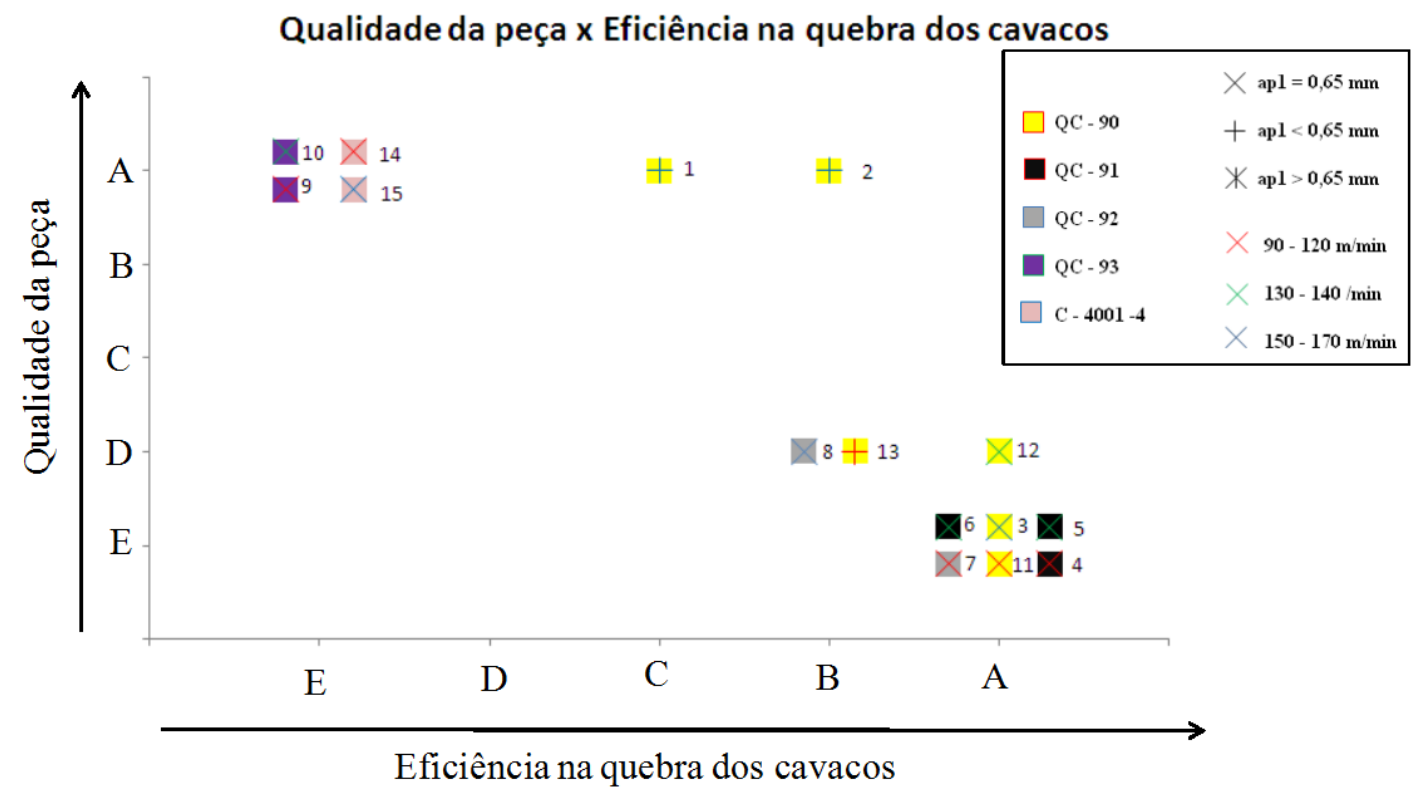

Figura 6: Qualidade da peça e eficiência na quebra dos cavacos obtidas na primeira etapa de testes. 


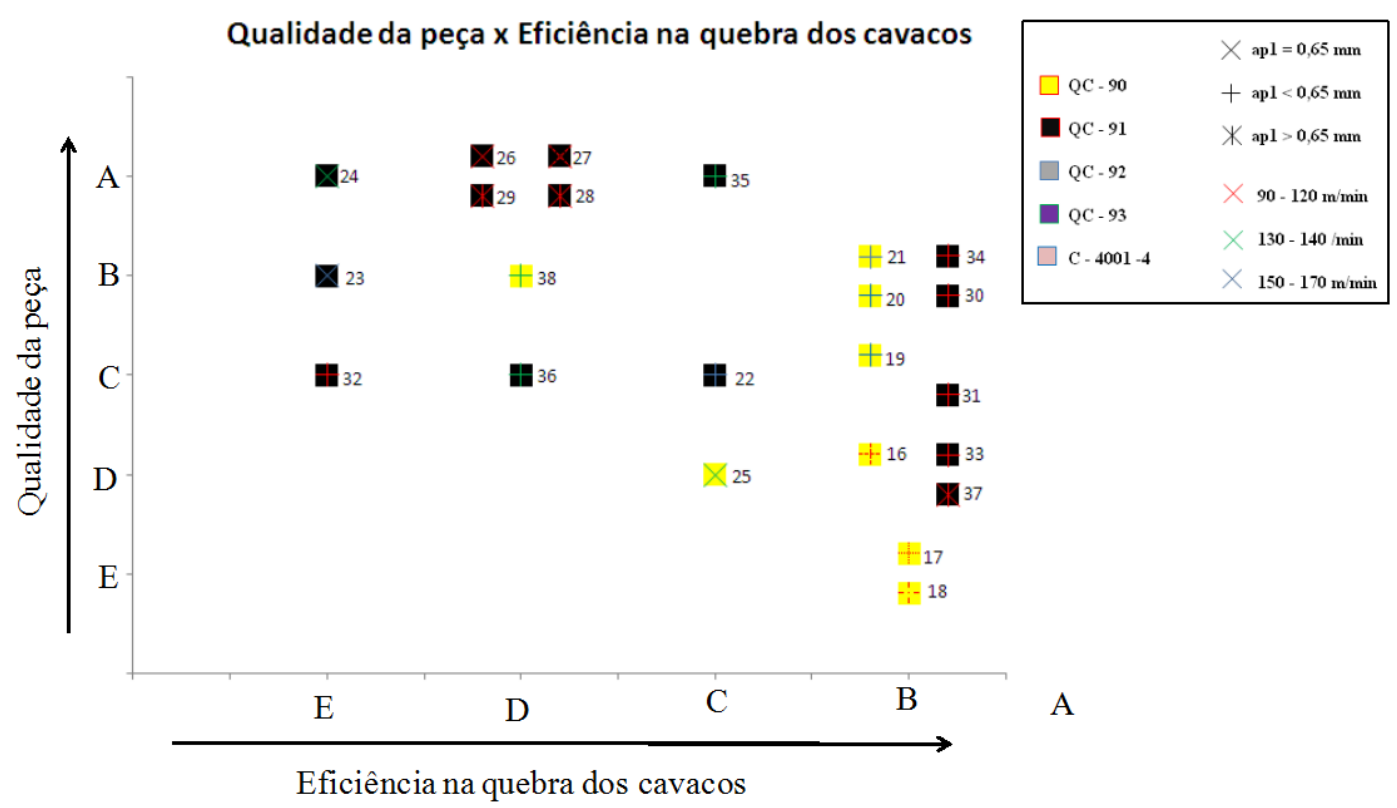

Figura 7: Qualidade da peça e eficiência na quebra dos cavacos obtidas na segunda etapa de testes.

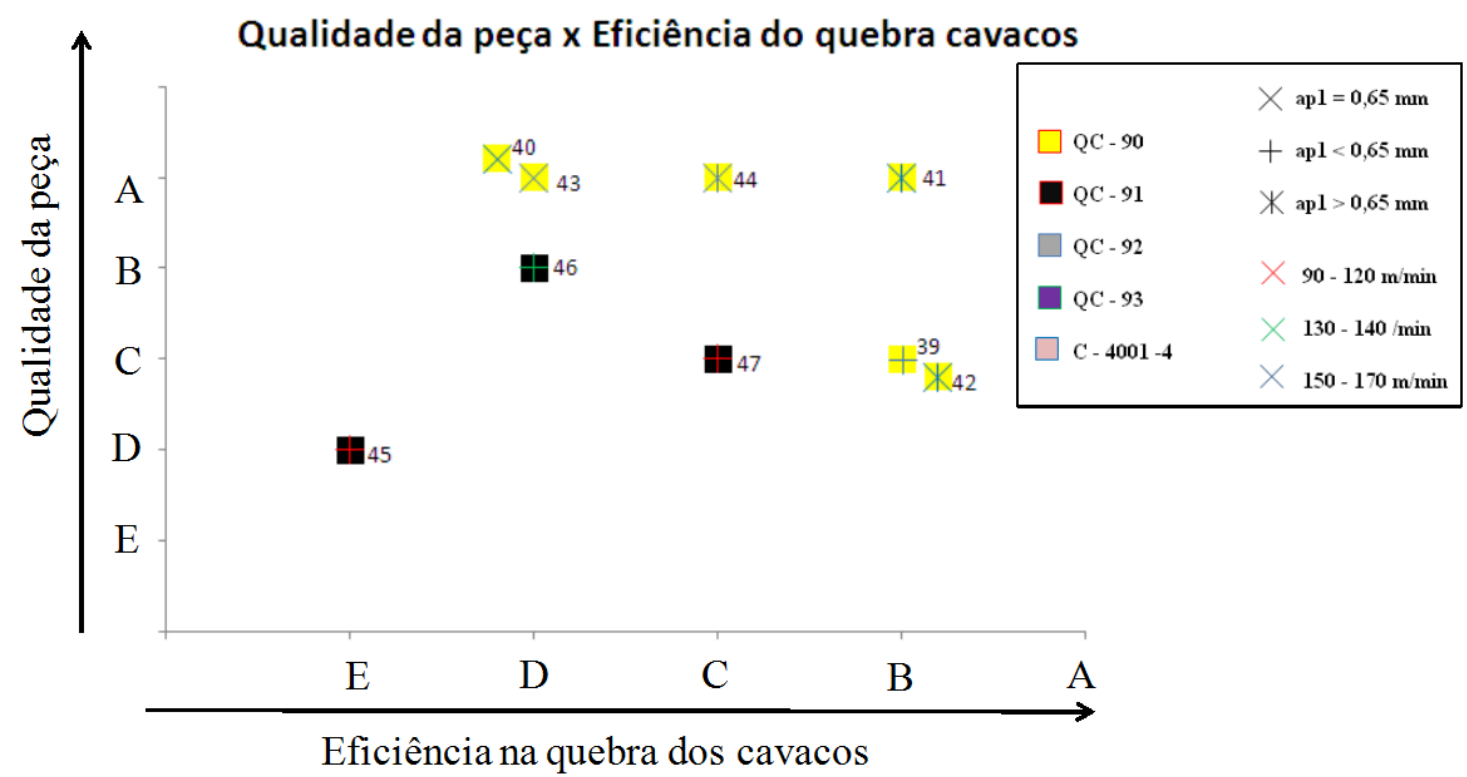

Figura 8: Qualidade da peça e eficiência na quebra dos cavacos obtidas na terceira etapa de testes.

A última fase do trabalho experimental consiste no monitoramento da corrente do motor do eixo principal usando o sistema de armazenamento de dados PIMS. O gráfico da Figura 9 representa a velocidade real do eixo principal (linha vermelha) e o percentual de potência nominal (45 kW) do motor do eixo do eixo principal consumido durante a operação de usinagem com o quebra-cavacos original (linha azul). A região que possui duas linhas verticais com valores para cada variável é a região que ocorre as duas passadas de desbaste de rosca. A Figura 10 mostra o mesmo resultado da Figura 9, porém empregando o quebra-cavacos QC-90. Os demais parâmetros foram mantidos ( $v_{c}=160 \mathrm{~m} / \mathrm{min}$ e $\left.a_{p 1}=0,65 \mathrm{~mm}\right)$. 


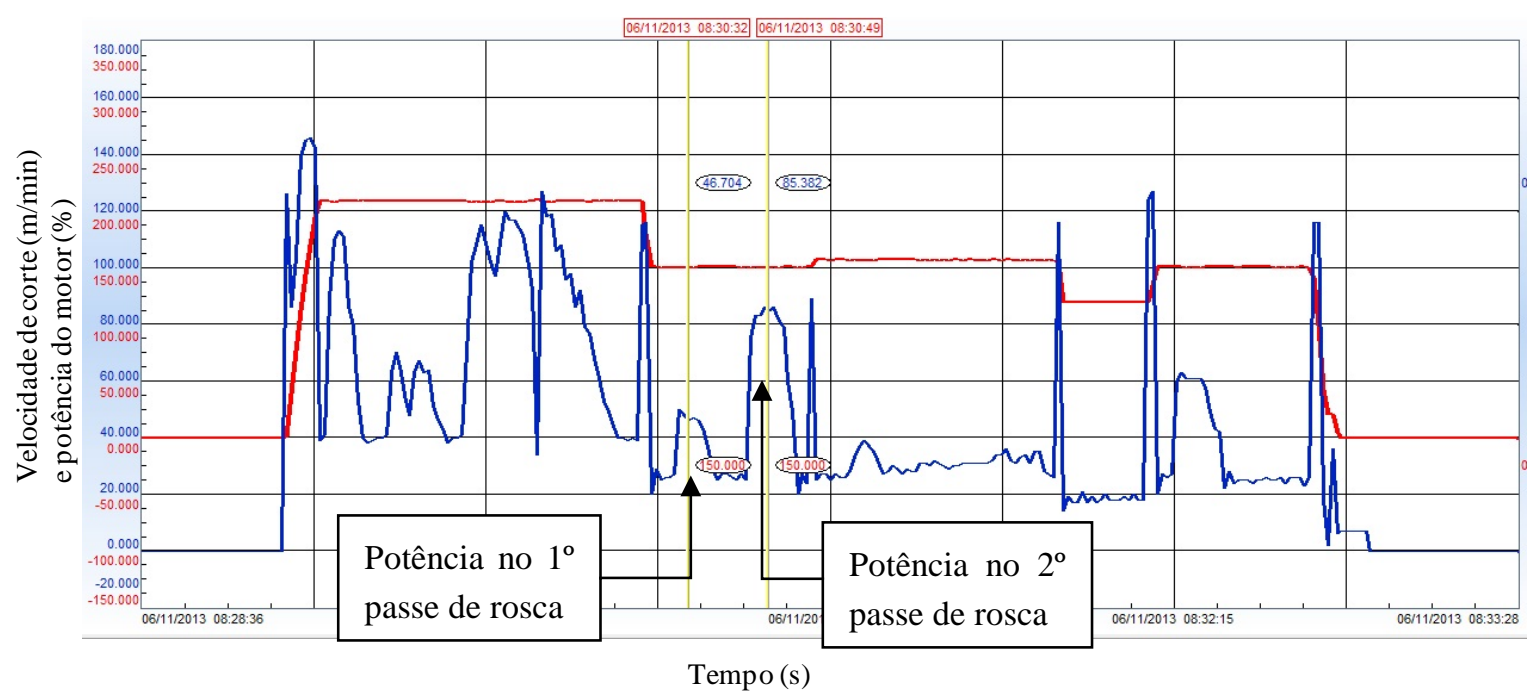

Figura 9: Carga no motor do eixo principal utilizando o quebra-cavacos original.

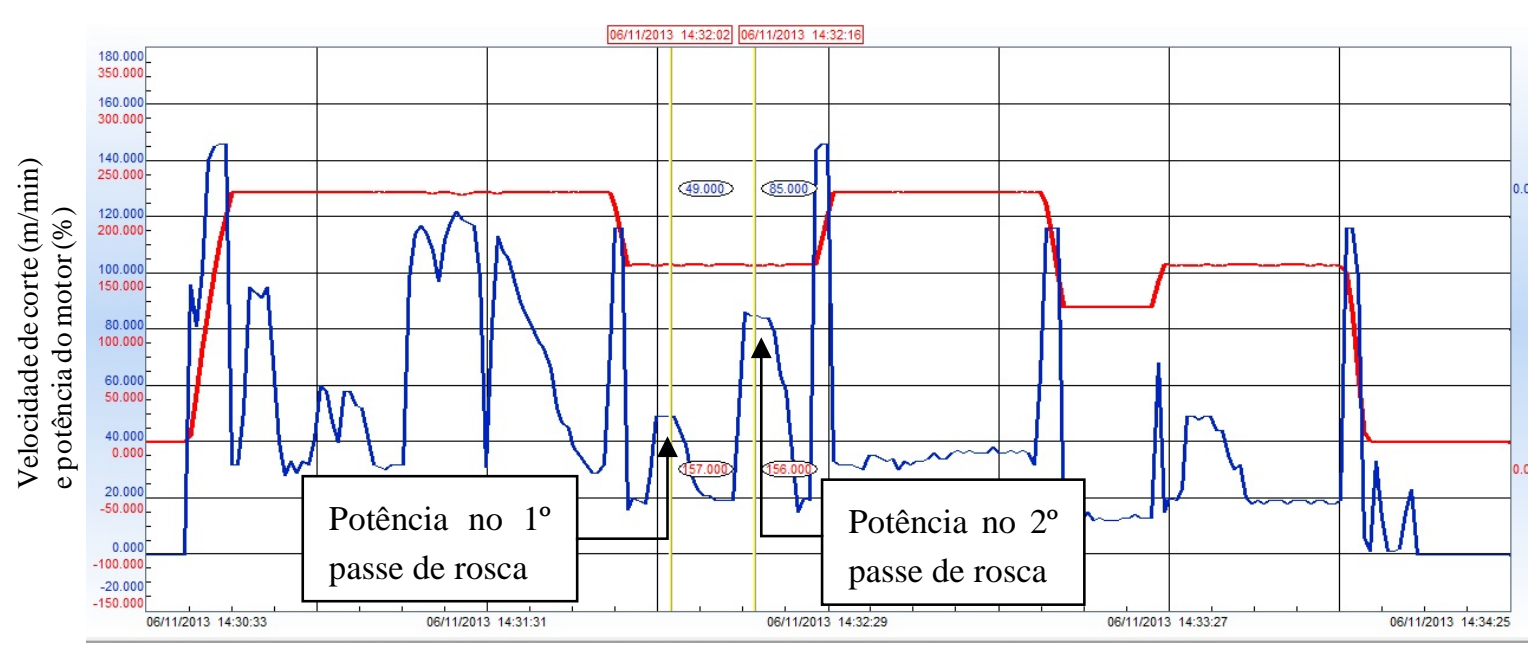

Tempo (s)

Figura 10: Carga no motor do eixo principal utilizando o quebra-cavacos QC-90.

\section{DISCUSSÃO}

Percebe-se pela Figura 6 que o quebra-cavacos QC-93 e o quebra-cavacos da Seco Tools não apresentaram sinal de trepidação, mas em contrapartida também não foram eficazes na quebra do cavaco. Baseado nesse resultado insatisfatório, esses dois quebra-cavacos foram eliminados das demais etapas de teste. Isso pode ser atribuído à distância da aresta de corte, uma vez que esses dois quebra-cavacos são os de maior distância. Esse resultado comprova a teoria apresentada por CHAWLA [] ] e DAS et al. [14] de que a distância do quebra-cavacos à aresta de corte é a variável mais influente na quebra do cavaco. Segundo NAKAYAMA [15], a fratura do cavaco ocorre quando a deformação que este está sofrendo é maior que o limite de ruptura. A deformação que o cavaco sofre é chamada de deformação de fratura $\left(\varepsilon_{b}\right)$ e depende do raio de curvatura $\left(R_{\text {cav }}\right)$ e da espessura do cavaco ( $h$ '), conforme demonstrado na EQUAÇÃO 1. Percebe-se que quanto menor o raio de curvatura do cavaco e maior a espessura do cavaco, maior será a deformação de fratura. Portanto, com intuito de quebrar o cavaco, deve-se aumentar a deformação de fratura por meio da redução do raio de curvatura do cavaco ou pelo aumento da sua espessura. A EQUAÇÃO 2 mostra a relação entre o raio de curvatura do cavaco e a distância do quebra-cavacos à aresta de corte $(W)$, a altura do quebra-cavacos $(H)$ e o comprimento da região de contato da ferramenta com o cavaco $\left(l_{n}\right)$. Percebe-se que quanto maior a altura e menor a distância do quebra-cavacos, menor será o raio de curvatura, maior será a deformação de fratura e consequente- 
mente maiores chances de quebra do cavaco.

$$
\begin{aligned}
& \varepsilon_{b}=\ln \left(\frac{R_{c a v}}{R_{c a v}-\frac{h^{\prime}}{2}}\right) \\
& R_{c a v}=\frac{\left(W-l_{n}\right)^{2}}{2 H}+\frac{H}{2}
\end{aligned}
$$

O quebra-cavacos QC-92 apresentou resultados próximos ao quebra-cavacos QC-91. Uma vez que a única diferença entre os dois quebra-cavacos é o chanfro no flanco lateral de cada dente, nota-se que essa variação no ângulo do flanco lateral de cada dente não influenciou no processo. Portanto, optou-se por eliminar também o quebra-cavacos QC-92 das etapas posteriores de testes. Os quebra-cavacos QC-90 e QC-91 foram os quebra-cavacos com maior eficiência na quebra dos cavacos, contudo as peças usinadas com esses quebra-cavacos foram as que apresentaram maior tendência de trepidação.

Apenas seis peças das 23 peças usinadas foram recusadas por trepidação durante a segunda etapa de testes. Isso significa que apesar de em algumas peças ter ocorrido um pouco de trepidação, estas ainda estavam dentro da tolerância aceitável, não sendo motivo de recusa das peças. Portanto, apesar da qualidade do acabamento superficial da rosca ficar inferior quando se utiliza o quebra-cavacos desenvolvido, as indicações de trepidado são apenas visuais e quando aplica-se o critério de passar uma ponta da lapiseira na região não ocorre nenhuma indicação de trepidação. Com relação à influência da velocidade de corte sobre a quebra do cavaco e qualidade da peça, nessa segunda etapa (Figura 7), nota-se uma tendência de piora na eficiência da quebra dos cavacos quando a velocidade aumentou de 100 para $140 \mathrm{~m} / \mathrm{min}$. Com relação à qualidade da peça, entretanto, percebe-se que o aumento da velocidade de corte tende a reduzir a trepidação, melhorando a qualidade da peça e reduzindo a probabilidade de rejeição. Não foi possível perceber nenhuma variação na quebra do cavaco e na qualidade da peça ao variar os valores de sobremetal. Contudo, sabe-se que valores de sobremetal de torneamento muito elevado (acima de $0,2 \mathrm{~mm}$ ) apresentam uma tendência de trepidação independentemente do tipo de quebra-cavacos utilizado. Por isso, durante os testes manteve-se a variação do sobremetal até $0,2 \mathrm{~mm}$ e nessa faixa de variação não foi encontrada nenhuma tendência.

A Figura 8 mostra a influência da profundidade de usinagem sobre a quebra do cavaco e a qualidade da peça. Os resultados encontrados nessa terceira etapa são contrários ao encontrado na segunda fase, uma vez que nessa etapa percebe-se que com o aumento da profundidade de usinagem no primeiro passe a quebra do cavaco melhorou. Com relação à qualidade da peça, percebe-se que não se deve trabalhar nos dois extremos de profundidade de usinagem do primeiro passo. Ou seja, tanto os valores muito baixos quanto os valores muito altos de profundidade de usinagem do primeiro passo de rosca são ruins para o quesito qualidade da peça. Portanto, os melhores valores de profundidade de usinagem do primeiro passe de rosca estão entre 0,65 $\mathrm{mm}$ e $0,8 \mathrm{~mm}$.

Os resultados apresentados comprovam a teoria que o material da peça, o avanço e a profundidade de usinagem são, nessa ordem, os parâmetros que mais influenciam a forma do cavaco. Contudo a velocidade de corte e o ângulo de saída da ferramenta também influenciam a forma do cavaco [16]. Em geral, a redução da velocidade de corte, o aumento do avanço, o aumento da profundidade de usinagem, ou a redução do ângulo de saída tendem a mudar a forma dos cavacos de fita para cavacos mais curtos. Apesar do material estudado neste artigo apresentar cavacos na forma de fita contínua, normalmente estudos mostram que os cavacos de aços temperados e revenidos tendem a ter forma mais curta [17] e [18].

Apesar da profundidade de usinagem $a_{p 1}$ aplicada ser $0,65 \mathrm{~mm}$, ou seja, as duas passadas de roscamento com a mesma profundidade, percebe-se na Figura 9 que a segunda passada de roscamento exigiu maior potência do motor do eixo principal (potência média de $21 \mathrm{~kW}$ na primeira passada e de $38 \mathrm{~kW}$ na segunda passada). Uma potência maior exigida na segunda passada de roscamento significa que um maior volume de material foi removido. Isso pode ser explicado, uma vez que na segunda passada de roscamento a ferramenta além de remover o material na região da crista da rosca, remove também o material na região do vale da rosca, aumentando assim a área de contato. Assim como no caso anterior, percebe-se na Figura 10 que a segunda passada de roscamento exigiu mais do motor do eixo principal (potência média de $22 \mathrm{~kW}$ na primeira pas- 
sada e de $38 \mathrm{~kW}$ na segunda passada). Além disso, percebe-se que os resultados obtidos de carga na Figura 10 são muito similares aos valores da Figura 9, indicando que apesar de uma melhor quebra do cavaco e uma maior tendência de trepidação com o quebra-cavacos desenvolvido, não ocorreram variações na carga do motor do eixo principal.

\section{CONCLUSÕES}

Recomenda-se o uso do quebra-cavacos QC-90 com velocidade de corte entre 150 e $160 \mathrm{~m} / \mathrm{min}$ e profundidade de usinagem do primeiro passe entre 0,65 e 0,8 mm para obtenção da melhor relação de eficiência na quebra do cavaco e qualidade da peça;

As variáveis distância da aresta de corte, profundidade de usinagem e velocidade de corte foram, nesta ordem, os parâmetros mais influentes na quebra dos cavacos e qualidade da peça;

Não foi possível encontrar nenhuma variação no consumo da potência do motor do eixo principal com o uso do quebra-cavacos QC-90 comparado com o quebra-cavacos original;

Finalmente, o quebra-cavacos desenvolvido melhorou a segurança dos operadores dos tornos e diminuiu as perdas por quebras das esteiras transportadoras de cavacos.

\section{AGRADECIMENTOS}

Os autores agradecem à Vallourec Tubos do Brasil e ao Programa de Pós-Graduação em Engenharia Mecânica da Universidade Federal de Minas Gerais pelo apoio à realização deste trabalho.

\section{BIBLIOGRAFIA}

[1] PETROBRAS. http://www.petrobras.com.br/ acessado em abril de 2014.

[2] JAWAHIR, I. S., VAN LUTTERVELT, C. A. "Recent Developments in Chip Control Research and Applications", Annals of the CIRP, v. 42 n. 2, pp.659-685, 1993.

[3] BAIRAMOV, G; ABDULALIEV, Z. É. "Optimization of cutting conditions and tool geometry in multiple threading of tool-joint threads", Traduzido de Khimicheskoe i Neftyanoe Mashinostroenie, n. 12, pp. 3537, 1965.

[4] SECO. Catálogo e Guia Técnico, 2006.

[5] EZUGWU, E. O., OKEKE, C. I., MACHADO, A. R. "High speed threading of inclusion-modified steels with coated carbide tools”, Journal of Materials Processing Technology , v. 86, pp. 216-225, 1999.

[6] CHAWLA, B. S. An analysis of strain in chip breaking using slip-line field theory with adhesion friction at chip/tool interface, Tese de D.Sc., The department of mechanical engineering National Institute of Technology Rourkela, India, 2005.

[7] SANDVIK. Manual Técnico - Tecnologia da Usinagem dos Materiais. 2010

[8] SAOTOME, T., YOKOI, F., KUMABE, J. "Precision internal threading of stainless steel”, Precision Engineering , v. 6, n. 2, pp.73-78, 1984.

[9] ZHOU, J. M., ANDERSSON, M., Stahl, J. E. “Cutting tool fracture prediction and strength evaluation by stress identification Part I: Stress model”, International Journal of Machine Tools and Manufacture, v. 37, n. 12, pp.1691-1714, 1997.

[10] CHEN, C., LIAO, C., LIAO, Y. "A method for determining the nose radius of an unequal nose radius multi-point threading tool”, Journal of Advanced Mechanical Design Systems and Manufacturing, v. 7, n. 2, 2013

[11] ZHOU, L. Machining Chip-Breaking Prediction with Grooved Inserts in Steel Turning, Tese de D.Sc., Worcester Polytechnic Institute, Estados Unidos, 2001.

[12] VALLOUREC. Especificação técnica do aço 4133 modificado. Documento de controle interno, 2014.

[13] DINIZ, A. E., MARCONDES, F. C., COPPINI, N. L. Tecnologia da usinagem dos metais, Artliber Editora, São Paulo, 2000.

[14] DAS, N. S., CHAWLA, B. S., BISWAS, C. K. "An analysis of strain in chip breaking using slip-line field theory with adhesion friction at chip/tool interface”, Journal of Material Processing Technology, v. 170, pp. 509-515, 2005.

[15] NAKAYAMA, K. “Chip Control in Metal Cutting”, Bulletin of Japanese Society of Precision

Engineering, v.18, n.2, pp.97-103, 1984. 
[16] MACHADO, A. R., ABRÃO, A. M., COELHO, R. T., et al., Teoria da Usinagem dos Materiais, 1ed., São Paulo: Ed. Blucher, 2009.

[17] KRAJNIK, P., KOPAC, J. “Modern machining of die and mold tools”, Journal of Materials Processing Technology, v. 157-158, pp. 543-552, 2004.

[18] BOING, D., BECKERT, S. F., OLIVEIRA, A. J. "Influência do tratamento térmico no aço-ferramenta AISI H13 em operação de fresamento com ferramenta de metal duro.” In: Anais do VI Congresso Nacional de Engenharia Mecânica, Campina Grande, 2010. 